\title{
TEN ARMS MEET TEN LEGS: DECAPODA (MOLLUSCA: CEPHALOPODA: SEPIOIDEA) SPAWN ON DECAPODA (CRUSTACEA: BRACHYURA: HOMOLIDAE)
}

\author{
C. L. McLay and D. Guinot
}

\section{A B S T R A C T}

\begin{abstract}
The first record of a homolid crab, Latreillopsis bispinosa, carrying cuttlefish eggs on its last pair of pereiopods is reported from the Philippine Islands. These eggs must have been laid directly on the crab by a species of Sepia.
\end{abstract}

The discovery of a homolid crab, Latreillopsis bispinosa Henderson, 1888, carrying cuttlefish eggs on its last pair of legs is as unlikely as it is curious. A mature female crab, measuring $16.6 \times 23.6 \mathrm{~mm}$ (carapace width $x$ carapace length), was collected by the MUSORSTOM 2 Expedition to the Philippine Islands, station CP20 (MNHN-B 13888), on 22 November 1980 from a depth of approximately $190 \mathrm{~m}$ (Guinot and Richer de Forges, 1995). This crab had two large black eggs, identified as belonging to Sepia sp., attached to each of its last pair of legs. Two eggs were attached at the proximal and distal limits of the carpal segments (Fig. 1). Those on the left leg and the proximal one on the right leg were intact, while the distal egg case on the right leg was empty. Dissection of the left proximal egg revealed a well-developed juvenile of Sepia sp. ready to hatch inside the tough, leathery capsule. Each egg, approximately 5 $\mathrm{mm}$ in diameter, was attached to the leg by means of a $1.5-\mathrm{mm}$ strap which wrapped around the carpus like a piece of Velcro ${ }^{\mathrm{TM}}$. Another smaller female crab, $8.1 \times 12.0 \mathrm{~mm}$, from the same station did not carry any egg cases.

An additional 19 females and 21 males of Latreillopsis bispinosa in the collection of the Museum national d'Histoire naturelle, Paris, did not carry any eggs. Although the egg-bearing crab was not the largest in the collection, it was among those in the largest size class.

Cuttlefish typically have large eggs that are laid individually and attached to various objects on the substrate, such as seaweed or gorgonians (Grimpe, 1926). When the egg is first laid, it has a flexible india rubber-like stalk, which is twined around the support and welded back on itself by the pair of long tentacles. The egg capsule and its strap, secreted by nidamental glands, quickly harden on exposure to the water. Aristotle referred to them as black myrtle berries (Lane, 1957) and these are sometimes also referred to as "raisins de la mer." Parental care is not a feature of cuttlefish females. It seems likely that the cuttlefish mistook the legs of Latreillopsis bispinosa for some sticks or worm tubes.

One of the egg cases of Sepia was empty, indicating that the eggs had been safely carried by the crab for a sufficient time to allow the juvenile cuttlefish to develop and hatch. Cuttlefish have direct development. Clearly, the use of a crab host by the cuttlefish was successful.

Dai and Yang (1991) reported an instance of a dromiid crab carrying squid eggs. A female, $8.4 \times 7.9 \mathrm{~mm}$, of Paradromia japonica (Henderson, 1888) (reported as Petalomera japonica) from Fujian, China, was carrying a group of eggs when captured in a squid trap. Dromiid crabs use their last two pairs of legs to carry sponges and ascidians to conceal themselves. In this case it would appear that the crab, which normally carries pieces of sponge, obtained the squid eggs from the trap wall rather than the eggs being laid directly on the crab itself. Among the other eggs inside the trap, the squid eggs would have afforded camouflage for the crab.

The only other known case of crabs carrying eggs is that of anomuran crabs of the family Lithodidae. Female liparid fishes of the genus Careproctus have a long ovipositor that is used in laying eggs inside the gill chamber of species of Lithodes, Paralithodes, and Paralomis (see Hunter, 1969; Peden and Corbett, 1973; Melville-Smith and Louw, 1987). Several hundred large fish eggs are deposited in the gill chamber of large lithodids, usually only one chamber being used by the fish. This one-sided relationship could, at best, be described as commensal. Like the cuttlefish, these fishes have direct development. While 


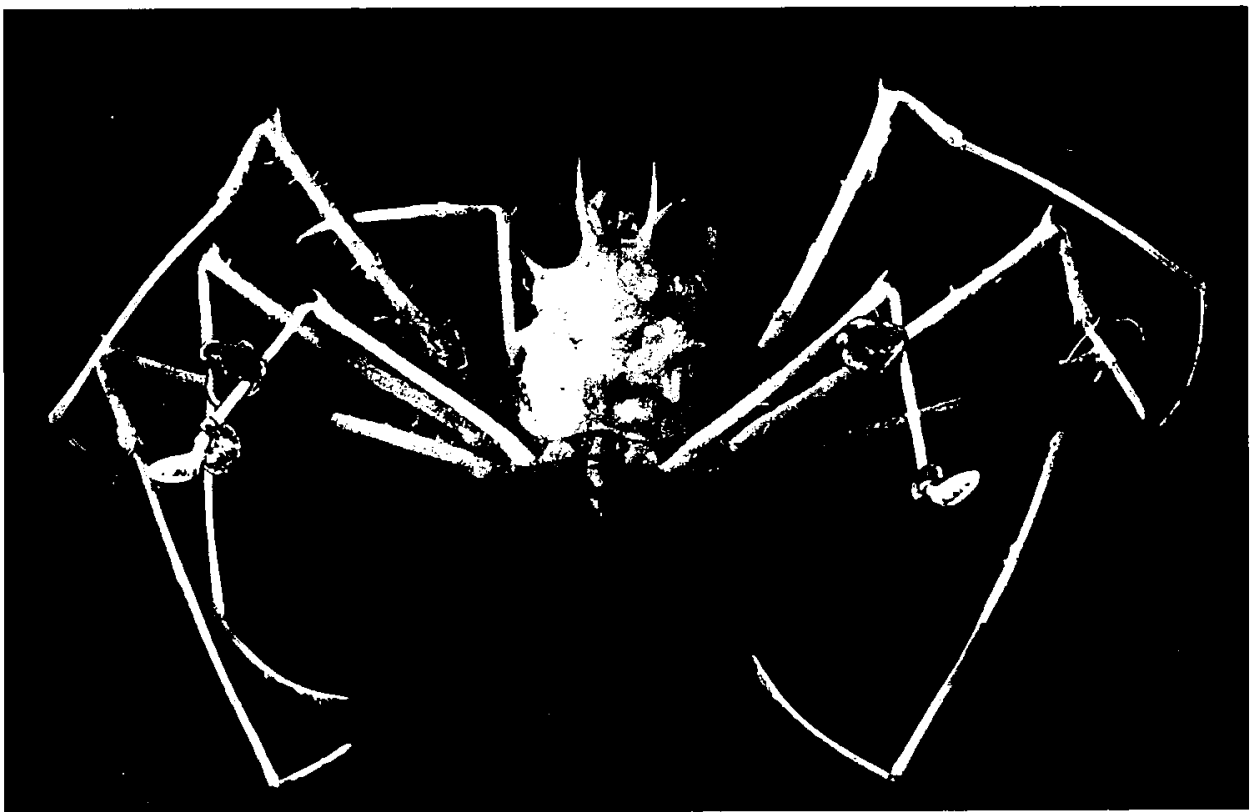

Fig. 1. Dorsal view of a female Latreillopsis bispinosa Henderson, $1888,16.6 \times 23.6 \mathrm{~mm}$, station CP 20 , MUSORSTOM 2 Expedition, Philippine Islands, $14^{\circ} 00.9 \mathrm{~N}, 120^{\circ} 18.2^{\mathrm{E}}, 192-185 \mathrm{~m}, 22$ November 1980, Guinot and Richer de Forges det. (MNHN-B 13888).

the use of crab legs by Sepia may well have been fortuitous, the widespread reports of liparid eggs from lithodid crabs indicates that this relationship is well established. The leech Notostomum cyclostoma (Johansson) from fjords in northern British Columbia opportunistically deposits its cocoons on the exoskeleton of Lithodes aequispinus Benedict, Paralithodes camtschatica (Tilesius), and Chionoecetes bairdi Rathbun (see Sloan et al., 1984).

Cuttlefish are efficient visual predators (Messenger, 1977) with very sensitive arms (Nixon and Dilly, 1977). Since their prey includes crabs, we must ask why the Sepia sp. deposited eggs on the crab, rather than eating it. It may have been because the crab was carrying something that deceived the cuttlefish.

Latreillopsis bispinosa has subchelate fifth pereiopods that should be capable of carrying a piece of camouflage. These are not as long as the preceding pereiopods, but shorter than. the first pereiopods, and always narrower than all other pereiopods. The fifth pereiopods are held subdorsally above the carapace. The camouflage would need to have been carried well above the body for the crab to escape detection. Guinot et al. (1995) reviewed the carrying behavior of homolid crabs and showed that the organisms carried include sponges, sea anemones, antipatharians, and gorgonids, although there are no records of what the species of Latreillopsis may carry.

\section{ACKNOWLEDGEMENTS}

We thank Dr. C. C. Lu, Museum of Victoria, Melbourne, for kindly identifying the eggs of Sepia and Jacques Rebiere for taking the photograph of Latreillopsis bispinosa.

\section{Literature Cited}

Dai, A., and S. Yang. 1991. Crabs of the China Seas.Springer-Verlag, Berlin, Germany. Pp. 1-608.

Grimpe, G. 1926. Biologische Beobachtungen an Sepia officinalis.-Verhandlungen der Deutschen zoologischen Gesellschaft 31: 148-153.

Guinot, D., and B. Richer de Forges. 1995. Crustacea Decapoda Brachyura: révision de la famille des Homolidae de Haan, 1841.- In: A. Crosnier, ed., Résultats des campagnes MUSORSTOM, Volume 13. Mémoires du Muséum national d'Histoire naturelle 13: 283-517.

, D. Doumenc, and C. C. Chintiroglou. 1995. A review of the carrying behaviour in brachyuran crabs, with additional information on the symbioses with sea anemones.-Raffles Bulletin of Zoology 43: 377-416.

Henderson, J. R, 1888. Report on the Anomura collected by HMS "Challenger" during the years 1873-76.- $\mathrm{Re}$ ports of Scientific Research of the Voyage of the Challenger 27(1): 1-221

Hunter, C. J. 1969. Confirmation of the symbiotic relationship between liparid fishes (Careproctus spp.) and 
male king crab (Paralithodes camtschatica).-Pacific Science 23: 546-547.

Lane, F. W. 1957. Kingdom of the octopus,-Jarrolds, London, England. Pp. 1-287.

Melville-Smith, R., and E. Louw. 1987. An association between a liparid fish species and the stone crab ( $\mathrm{Li}$ thodes tropicalis (Decapoda, Anomura).--South African Journal of Zoology 22: 140-142.

Messenger, J. B. 1977. Prey-capture and learning in the cuttlefish, Sepia.-Symposia of the Zoological Society of London 38: 347-376.

Nixon, M., and P. N. Dilly. 1977. Sucker surfaces and prey capture.-Symposia of the Zoological Society of London 38: 447-511.

Peden, A. E., and C. A. Corbett. 1973. Commensalism between a liparid fish, Careproctus sp., and the litho- did box crab, Lopholithodes foraminatus.-Canadian Journal of Zoology 51: 555-556.

Sloan, N. A., S. M. Bower, and S. M. C. Robinson. 1984. Cocoon deposition on three crab species and fish parasitism by the leech Notostomum cyclostoma from deep fjords in northern British Columbia.-Marine Ecology Progress Series 20: 51-58.

RECEIVED: 23 January 1997.

ACCEPTED: 24 March 1997.

Addresses: (CLMcL) Department of Zoology, University of Canterbury, PB 4800, Christchurch, New Zealand; (DG) Muséum national d'Histoire naturelle, Laboratoire de Zoologie (Arthropodes), 61 rue Buffon, 75005 Paris, France. 